\title{
Factors Affecting Contraceptive Use in Pakistan
}

\author{
NAUSHIN MAHMOOD and KARIN RINGHEIM
}

\begin{abstract}
Using data from the Pakistan Demographic and Health Survey of 1990-91, this study examines the effect of selected socio-cultural and supply factors on contraceptive use as reported by married women of reproductive ages. In addition to the expected positive relationship of woman's age, number of living children, education, and place of residence with contraceptive use, it is theorised that there are five factors potentially affecting fertility regulation in the socio-structural context of Pakistan. These include the extend of communication between husbands and wives, religious beliefs, female autonomy, son preference, and the family planning service and supply variables. Using logistic regression analysis, the results of the study indicate that the explanatory power of these five factors is significant in affecting the use of contraception in both urban and rural areas. While knowledge of a source for family planning is the strongest predictor of contraceptive use, husband-wife communication and religious attitudes are also significant. The fact that the inclusion of the theoretical variables dampens the predictive effect of the primary and secondary education for women leads to the speculation that while the extremely low levels of literacy among women must be addressed through government commitment to universal education, scarce family planning programme resources can be focused more effectively on promoting spousal communication, about family size and contraceptive use, and on soliciting the support of religious leaders to counteract the misperceptions about Islamic teachings on family planning and reliance on fate. With high quality and accessible services, these measures could go a long way towards providing couples with the means to meet their reproductive goals.
\end{abstract}

\section{INTRODUCTION}

The high rate of population growth in Pakistan and its adverse impact on the successful implementation of development strategies have long been recognised. In

Naushin Mahmood is Senior Research Demographer at the Pakistan Institute of Development Economics, Islamabad. Karin Ringheim is a Social Scientist affiliated with the USAID, Department of Population Research, Washington, D. C.

Authors' Note: The above is a revised version of a paper presented at the 22nd Population Conference of the International Union for the Scientific Study of Population (IUSSP), held in Montreal, August 24 - September 1, 1993. Permission for the use of the PDHS data was granted by the National Institute of Population Studies, Islamabad. The authors wish to thank Dr Mohammad Irfan and Mr Ghulam Yasin Soomro for their valuable comments and suggestions on an earlier draft of the paper. The comments of the anonymous referees are gratefully acknowledged. However, the views expressed in this paper are entirely those of the authors themselves. 
view of this, the government initiated a national family planning programme in the early sixties to reduce fertility levels. After nearly three decades of family planning activities and numerous small-scale non-governmental family planning projects, the contraceptive prevalence rate rose from 5 percent in 1974-75 [Pakistan Population Planning Council (1976)] to 18.7 percent in 1994-95 [Ministry of Population Welfare (1995)]. The total fertility rate has shown only a gradual decline from 6.3 lifetime births per woman in 1974-75 to 5.4 births in 1990-91 [National Institute of Population Studies (1992); Afzal et al. (1993)]. There is, however, evidence that a significant proportion of women do not want to have more children. Yet a majority of these women do not use contraception to avoid future births [Mahmood (1992)]. ${ }^{1}$ This apparently poor performance of the programme poses a challenge: How to increase contraceptive use levels and accelerate fertility decline? The challenge is even more serious when we consider that other Muslim countries with similar socio-economic conditions, like Bangladesh and Indonesia, and neighbouring India, have been successful in achieving distinctly higher levels of contraceptive prevalence and thereby lowering fertility rates in the last decade.

Given this situation, it becomes crucial to determine what policy prescriptions would be more effective in changing the fertility behaviour of Pakistani couples. On the one hand, it is argued that the social and cultural conditions which constrain the use of family planning must be evaluated and changed to generate more than a marginal decline in fertility. On the other hand, the emphasis on the provision and improvement of supply-side activities of family planning is considered important for an increased and sustained use of contraceptives even with low levels of socio-economic development and casual attitudes towards fertility control.

The social set-up and the developing nature of Pakistan's economy, together with a high desired family size, provide the traditional scenario where it becomes difficult to motivate couples to adopt contraception. As many of the family planning activities are concentrated in urban localities, the access to the family planning services is inadequate for a majority of the rural population. It has been argued that the lack of success of the population programme in Pakistan has largely been due to limited and inefficient supply of services [Robinson et al. (1981); Rukanudin and HardeeCleaveland (1992)]. The official family planning programme has been subjected to frequent changes in management strategies, without the earlier activities having been fully implemented. ${ }^{2}$ Improving the coverage and supply strategies further and increasing the use of effective contraceptives are, therefore, viewed as a policy priority.

In dealing with the question of raising the level of contraceptive use in Pakistan, it is worthwhile to understand what factors are significant in promoting the practice of

\footnotetext{
${ }^{1}$ Changes in selected indicators of fertility and family planning, as estimated from various surveys in Pakistan, are given in the Appendix Table 1.

${ }^{2} \mathrm{~A}$ detailed review of the history of the family planning programme in Pakistan, its management, and implementation is given in Robinson et al. (1981) and Rukanudin and Hardee-Cleaveland (1992).
} 
family planning. The apparent unmet need among a substantial proportion of women provides us the basis for identifying factors affecting the demand for contraception and, ultimately, for selecting programme and policy interventions that would better assist couples to meet their reproductive goals. The key question, therefore, is to investigate how various measures of social, cultural, and supply factors affect the use of contraception in the socio-structural context of Pakistan. These concerns need to be analysed both for urban and rural areas separately as women residing in the two types of area differ with respect to their background characteristics, reproductive attitudes, and family planning behaviour.

\section{THEORETICAL CONTEXT}

There is an evidence for high desired family size and strong son preference among Pakistani couples [Khan and Sirageldin (1977); Mahmood (1992); Ali and Rukanudin (1992)]. These types of preferences could be associated with the predominantly agricultural economy where children are valued highly for their contribution to farm work. As the majority of the population in Pakistan resides in rural areas characterised by inadequate basic infrastructure and social services, the low level of education and literacy, particularly in the case of women, perpetuates the gender inequality through differential access to education for boys and girls. The relatively less favourable position of women in the economic and decision-making spheres inhibits them from making choices about family size and the use of family planning methods. Under these circumstances, typically associated with low contraceptive use and high fertility, a clearer understanding of the role of social and cultural forces, jointly with the provision of family planning supply services, provides an important basis to judge the variations in contraceptive use across different population groups.

In this context, we theorise that there are five factors potentially affecting contraceptive use, in addition to the expected positive relationship of age of women, number of living children, urban residence, and education. Deriving from both the sociological and cultural perspectives [Coale and Watkins (1986)], these five factors include the extent of communication between spouses, son preference, religious beliefs, female autonomy, and family planning service supply variables. The rationale and the theoretical relationships for each factor are discussed below which would be tested empirically in the data. ${ }^{3}$

\footnotetext{
${ }^{3}$ It may be borne in mind that the data available in the Pakistan Demographic and Health Survey (PDHS) used in the analysis is not the most ideal and comprehensive to test our hypothesis in terms of the contextual or socio-cultural effects. However, it is not only the current best source of data for analysing the determinants of contraceptive use but also for information on certain theorised variables that have not been utilised and tested before. We attempt to maximise the information that the PDHS does offer to address our research question and to demonstrate that, despite its limitations, the data do signify useful findings for policy-makers and service providers.
} 


\section{Level of Husband-wife Communication}

Interspousal communication has been found to be associated with favouring a fewer number of children and with enhancing the practice of contraception. If couples can openly discuss their desires and aspirations for children with each other, a smaller family norm may emerge. But communication between husband and wife may be hampered by social norms of modesty and privacy concerning sexuality, as well as by the subordinate status of women.

In countries where the fertility transition has already been completed, husbandwife communication about family planning and desired family size is the norm. A national survey in Korea found that 78 percent of currently married women had discussed family size with their husbands [Oh (1988)]. Mutual influence occurring through two-way communication has been identified as the most important source of agreement in desired fertility among U.S. couples [Thomson (1986)]. It has also been demonstrated that where husband and wife are in disagreement about desired family size, the husband has greater influence in fertility outcomes [Mitchell (1972); Thomson, McDonald and Bumpass (1988)].

In contrast, the level of spousal communication about family planning in developing countries has been found to be very low. The evidence indicates that lack of communication between wife and husband is a major factor constraining contraceptive use [Mukerjee (1975); Bertrand et al. (1982); Pineda et al. (1981); Raju (1987)]. A Turkish study [Olson (1976)] found that husband-wife communication was more essential to contraceptive use in the rural than in the urban areas. This is due to the difficulty of obtaining contraceptives in the rural areas which required more cooperation between the couples in order to do so.

Although some women attempt to use contraception without their husband's knowledge, many forms of contraception require partner's participation or concurrence. Eighty percent of women in a Sri Lankan study of the potential demand for Norplant stated that they would need to discuss their interest with their husbands and the extent of communication was positively related to the wife's level of education [Thapa, Lampe and Abeykoon (1992)].

The limited evidence for Pakistan indicates that the use of contraception is strongly related to communication between spouses [Shah (1974)]. Past research also shows that the role of husbands in household and reproductive decision-making is significant [Mahmood and Ringheim (1993)], and women often mention their husband's disapproval of family planning as one of the reasons for non-use of contraception [National Institute of Population Studies (1992)]. Using the available information on husband-wife communication about family planning matters, an empirical examination of the question whether interspousal communication promotes mutual agreement in family size desires and the use of contraception among couples would be of special significance for Pakistan's demographic concerns. 


\section{Son Preference}

Although the influence of a preference for sons has not been shown to have a pronounced effect on contraceptive use or fertility in most countries, Pakistan is one of the few where son preference is still evident in excess female mortality among female infants and children both historically and in the present [Arnold (1992)]. In a review of the survey data on sex preference, Nag (1991) found that a preference for sons was higher in Pakistan than in neighbouring India and Bangladesh, based on the evidence that the number desiring no more children was higher for those with more sons, as well as the higher mortality for female than male children of 1 to 4 years old. As for the role of son mortality in influencing contraceptive use behaviour, the limited evidence for Pakistan suggests that the two variables are negatively related. The effect, however, is not significant when controlled for socio-economic factors [Shreeniwas and Mahmood (1995)]. The results of a study in Bangladesh showed that the mortality of sons, and not daughters, was associated with a lower rate of female contraceptive use and a higher rate of discontinuation [Johnson and Sufian (1992)].

Sex preference has influence on birth outcomes in a natural fertility regime, but in a society still near the onset of fertility transition, it may influence whether and at what parity contraceptive use is initiated [Niraula and Morgan (1994); Rahman and DaVanzo (1993)]. Early contraceptive adopters are likely to be those of relatively high parity who believe they have a sufficient number of sons, as would be the case in Pakistan. Given the low level of contraceptive use among women, our expectation is that the impact of the number of living sons on contraceptive use will be relatively small, but will be greater than that of living daughters.

\section{Religious Beliefs/Values}

It is argued that religious beliefs in Pakistan are not favourable to the practice of family planning and contribute to a lack of self-efficacy in limiting family size. Based on the information from the Pakistan Demographic and Health Survey of 1990-91, about 13 percent of women cite "religion" as a reason for not intending to use contraception in the future, while the percentage among husbands is higher, (18 percent generally and 22 percent for husbands over 30 of age). In terms of 'the ideal number of children', about 60 percent of both husbands and wives give "up to God" as a response; this percentage is unprecedented in both previous national surveys and among the 30 other DHS country surveys that have been completed thus far [Ali and Rukanuddin (1992)]. ${ }^{4}$

${ }^{4}$ The possible explanations for a higher percentage of responses to the question on the ideal family size could be associated with the high level of illiteracy, cultural conservatism, among older people in particular, and a general apathetic attitude among couples to give numeric answers to family size questions. Moreover, women with larger number of children are more likely to give the "up to God" responses, as has been found in the preliminary data analysis. 
Preconditions to contraceptive use stipulated by Coale indicate that unless the concept of fertility control has been entertained and perceived to be advantageous, contraceptive-seeking behaviour cannot occur. For individuals who consider that fertility is controlled by fate, the ideal of "preferences" for family size or the approval and use of family planning may be meaningless [Kane and Larson (1982)]. Given that a substantial proportion of women have cited religion as a reason for not using contraceptives, and consider fertility as being controlled by fate, we test the hypothesis whether religious attitudes are significant in reducing the likelihood of contraceptive use.

\section{Female Autonomy}

The status of women in Pakistan, as measured by the educational level and participation in the paid labour force, is inarguably low. Based on the Pakistan Demographic and Health Survey of 1990-91, nearly 80 percent of ever-married women of ages 15 to 49 years report having no formal education at all. Only 9 percent of women have secondary or higher levels of education, inevitably linked to a very small percentage of women in professional employment. Illiteracy not only greatly constrains the modes of communication available to reach women but also prohibits women's access to a world of ideas, and allows them access to information only as filtered through their husbands and other relatives/friends.

Moreover, family structure in Pakistan is patriarchal and patrilocal, with strong family ties and kinship values. Marriages are mostly contracted between relatives and families and women are likely to have less autonomy in the extended than in a nuclear households. Those women who are exposed to the outside world and are able to go out independently have greater awareness and may have a greater say in family decisionmaking. Acknowledging the limitations of the indicator variable to represent autonomy, ${ }^{5}$ we propose that self-sufficiency to negotiate in the public realm and exposure to places outside the home is one aspect of female autonomy, and that such exposure or autonomy will increase the probability of use of contraception.

\section{Family Planning Services}

From a global perspective, Pakistan is clearly on the low end of the programme effort. Although 60 percent of Pakistani women either desire no more children or want to delay their next birth, only 20 percent have access to family planning services [National Institute of Population Studies (1992)]. In general, quicker and easy access can be expected to lead to greater contraceptive use [Bulatao (1993)]. The shortage of family planning service outlets is especially severe in the rural areas of Pakistan, where the great majority of the population lives.

${ }^{5}$ The only measure of autonomy in the Pakistan DHS is whether a woman would be able to go to a hospital or clinic alone or would need to be accompanied. This, therefore, is our sole measure of female autonomy. 
Personal contact is perhaps the most effective mechanism for conveying family planning information, but the media has also been a successful channel for reaching large numbers of people. Contact either with a programme worker or exposure to the family planning massage through media have been found to be critical factors in increasing contraceptive use among a sample of Pakistani women who want no additional children [Mahmood (1992a)].

Where people's attitudes towards family planning need to be changed, as they do in Pakistan, a logical first step of a media campaign would be to increase public approval [Bulatao (1993)]. In El Salvador, when contraceptive prevalence was 35 percent, over 90 percent of reproductive-aged women reported having heard a media message concerning family planning [Bertrand et al. (1982)]. In Pakistan, by contrast, with current usage at 14 percent, only 21 percent of the women have reported having heard a media message in the past month [National Institute of Population Studies (1992)].

The role of family planning service supply variables, measured in terms of the knowledge of and ease of access to a service outlet, as well as exposure to a media message about family planning, is expected to promote the use of contraception.

\section{DATA AND METHODS}

The data for the present analysis are drawn from the Pakistan Demographic and Health Survey (PDHS) of 1990-91, a nationally representative survey of 6,611 evermarried women aged 15-49 years. The survey was based on a two-stage stratified random sample of households covering the four regions and urban-rural areas of Pakistan. The data collected in the survey provides extensive information on the reproductive history, family size preferences, contraception, child nutrition, health, and socio-economic background characteristics of married women. To find explanations for the variation in contraceptive use, currently married non-pregnant and fecund women are selected for the analysis. We, therefore, have a sample of 5,232 women, of which 1,628 are urban and 3,604 rural.

A multivariate analysis is undertaken to study the relationship of a set of explanatory variables with current contraceptive use. The regression models are estimated separately for the urban and rural areas to see if the factors determining contraceptive use are basically similar or different in the two types of urban and rural settings.

\section{Dependent Variable}

Contraceptive use is measured as a dichotomous dependent variable that takes the value of 1 if the respondent is currently using contraceptives; zero otherwise. Only non-pregnant, non-sterilised women were asked the question on current use: “Are you 
currently doing something or using any method to delay or avoid getting pregnant?”. The analysis, thus, pertains to non-pregnant women currently using any method of contraception. Because of the binary nature of the dependent variable, logistic regressions are used for the analysis.

The logits, as opposed to proportions, will give prediction of coefficients bounded by zero or one in the probability metric. The estimated coefficients, which have positive and negative signs, indicate the magnitude of the increment in the logodds of contracepting with a unit change in the explanatory variable.

\section{Explanatory Variables}

Women's current age, living children, women's and husband's education and place of residence are used as control variables for predicting use. Education is measured as a three-category dummy variable, representing 'no education', 'primary/middle', and 'secondary and higher', with the expectation that completing a certain level of education may be critical in promoting contraceptive adoption behaviour. Place of residence is categorised as 'always urban' and 'rural to urban migrants' as against the 'rural' as a reference category to see how much urban exposure is important in differentiating contraceptive use among women.

In addition to these socio-demographic background variables, other theorised variables to explain the variations in contraception use are husband-wife communication, preference for sons, religious beliefs, female autonomy, and three family planning service variable.

Husband-wife communication is measured as a binary variable based on responses to four questions in which no communication is given the value equal to 1 on any one of the four questions, and zero otherwise. The four questions and the percentage of responses to each question among wives are shown in Table 1. Overall, nearly 82 percent of wives had never discussed or did not know their husband's views on one or more questions indicating interspousal communication. We expect that women having no communication are less likely to use contraceptive than those who have discussed or talked about family planning or desired family size with their husbands.

Son preference is measured by including as independent variables the number of living sons and living daughters in the model, and by comparing the size of the two coefficients to determine which one has the greater influence [Nag (1991)]. We expect that both coefficients will be positively related to contraceptive use. However, the size of the coefficients for the number of living sons is expected to be larger than that for daughters.

Religious belief is measured on the basis of "up to God" responses to two questions being asked of the respondents. The questions indicating religious beliefs and 
Table 1

The Measurement and Percentage Response to Selected Theoretical Variables and Other Characteristics of Currently Married, Non-pregnant Fecund Women Aged 15-49 Years: PDHS 1990-91

\begin{tabular}{|c|c|}
\hline Variables and Their Measurement & Total $(\mathrm{N}=5232) \%$ \\
\hline \multicolumn{2}{|l|}{ Questions Indicating Interspousal Communication } \\
\hline $\begin{array}{l}\text { 1. Do you think that your husband approves or disapproves of couples using a method to avoid } \\
\text { pregnancy? (don't know) }\end{array}$ & 31.3 \\
\hline $\begin{array}{l}\text { 2. How often have you and your husband talked about family planning in the past year? } \\
\text { (never) }\end{array}$ & 74.3 \\
\hline $\begin{array}{l}\text { 3. Have you and your husband ever discussed the number of children you would like to have? } \\
\text { (no) }\end{array}$ & 62.6 \\
\hline $\begin{array}{l}\text { 4. Do you think your husband wants the same number of children that you want, or dose he } \\
\text { want more or fewer than you want? (don't know) }\end{array}$ & 34.3 \\
\hline Husband-wife Communication (1=none; $0=$ some) & 81.9 \\
\hline \multicolumn{2}{|l|}{ Questions Indicating Religious Beliefs } \\
\hline $\begin{array}{l}\text { 1. Would you like to have (a/another) child or would you prefer not to have any (more) } \\
\text { children? (up to God) }\end{array}$ & 12.0 \\
\hline $\begin{array}{l}\text { 2. If you could choose exactly the number of children [to have] in your whole life, how many } \\
\text { would that be? (up to God) }\end{array}$ & 59.7 \\
\hline Religious Beliefs (1=up to God; $0=$ otherwise $)$ & 60.0 \\
\hline \multicolumn{2}{|l|}{ Female Autonomy } \\
\hline (1=Could go to hospital alone; $0=$ otherwise) & 25.6 \\
\hline \multicolumn{2}{|l|}{ Family Planning Programme Variables } \\
\hline \multicolumn{2}{|l|}{ Do you know where a person could go to get (Method)? } \\
\hline Knows Source of Service Outlet $(\mathbf{1}=\mathbf{y e s} ; \mathbf{0}=\mathbf{n o})$ & 47.3 \\
\hline \multicolumn{2}{|l|}{ It is easy or difficult to get there? } \\
\hline Easy Access to Service Outlet (1=easy; $\mathbf{0}=\mathbf{o t h e r w i s e})$ & 20.4 \\
\hline \multicolumn{2}{|l|}{ In the last month, have you heard a message about family planning on: radio? television? } \\
\hline Heard FP message on TV or radio $(\mathbf{1}=\mathbf{y e s ;} \mathbf{0}=\mathbf{n o})$ & 21.6 \\
\hline \multicolumn{2}{|l|}{ Place of Residence } \\
\hline Rural & 31.1 \\
\hline Urban & 68.9 \\
\hline \multicolumn{2}{|l|}{ Wife Education } \\
\hline None & 78.5 \\
\hline Primary/Middle & 13.8 \\
\hline Secondary and Higher & 7.7 \\
\hline \multicolumn{2}{|l|}{ Husband Education } \\
\hline None & 47.9 \\
\hline Primary/Middle & 28.6 \\
\hline Secondary and Higher & 23.5 \\
\hline \multicolumn{2}{|l|}{ Region of Residence } \\
\hline Punjab & 59.7 \\
\hline Sindh & 23.2 \\
\hline NWFP & 13.4 \\
\hline Balochistan & 3.7 \\
\hline \multicolumn{2}{|l|}{ Other Characteristics } \\
\hline 4 or more children & 48.3 \\
\hline Knowledge of any method & 78.2 \\
\hline Current use & 14.4 \\
\hline Ever use & 22.4 \\
\hline Intend to use in next 12 months & 7.6 \\
\hline Want no more children & 38.9 \\
\hline
\end{tabular}

Source: Pakistan Demographic and Health Survey, 1990-91. 
the percentage of women giving "up to God" responses are shown in Table 1. Women believing in fate about the control of their fertility are assumed to have strong religious attitudes/values and are coded as 1 against zero for 'all others'. The relationship of religious attitudes with use is expected to be negative.

Female autonomy is measured by using one question which directly indicates the extent of female independence, and that is whether the wife could go to a health clinic or hospital by herself or would need to be accompanied by someone. Although we assume that the level of female education is a measure of autonomy, yet it is also entered as a control variable to compare the effect of education in relation to theoretical variables. The effect of the female autonomy variable on the dependent variable is expected to be positive.

Family planning variables are measured in three separate dichotomous variables. The first one is the 'Knowledge of Source', indicating whether the individual knows where to go to get a modern method of contraception. The second one is 'Easy Access', showing whether the source is perceived as being easy or difficult to reach. The third one is measured as 'Media', indicating whether or not the individual has heard a message concerning family planning on either the radio or the television in the last month. The questions regarding these three variables and the percentage responding as "yes" to the question are shown in Table 1. Each of the programme service variables is expected to be positively related with the dependent variable.

\section{RESULTS}

Table 1 describes the measurement and the percentage response to selected theoretical variables and other socio-economic characteristics of the selected sample of currently married women. As Table 1 shows, about 74 percent of women have never talked about family planning with their husbands in the past year, and 62.6 percent have reported no discussion about the number of children they would like to have. Overall, nearly 82 percent of women appear to have no communication with their husbands about family planning matters. Believing in fate or "upto God" responses to the question on the ideal number of children are nearly 60 percent. As for female independence/autonomy, 25.6 percent of women report that they could go unaccompanied to a hospital/clinic. Regarding family planning information, about 47 percent of married, reproductive-aged women know of a source of a service outlet, and access to this source is described as 'easy' by only 20.4 percent of these women, while 21.6 percent of the women have heard a family planning message on the radio or T.V. Table 1 also describes the proportions of women by education categories, place and region of residence, and some other characteristics. We may note that although 78

percent of the women selected in the sample have no formal education, knowledge about any method is widespread (78.2 percent), with 14 percent reporting current use 
and 22.4 percent ever-use of contraceptive. Moreover, nearly 39 percent want no future births, and only 10 percent indicate an intention to use a method in the near future.

Table 2 presents contraceptive prevalence among selected sub-groups of women by place of residence. The overall level of contraceptive use is quite low among Pakistani couples: only 14.4 percent of currently married, non-pregnant fecund women reported that they are currently using any method, which is 7.1 percent for rural women as compared to 30.4 percent for urban women. As expected, there are great variations in use by selected theoretical variables and socio-demographic characteristics of women for both urban and rural women. Despite the fact that a very small proportion of rural women are users, 26 percent of those with secondary and higher education and 37 percent of those communicating with husbands are users. The corresponding percentages for urban women are much higher, 45.9 and 62.0, respectively. Regarding variations in use by family planning variables, 18.2 percent of rural women with knowledge of a source outlet and 14.4 percent of those who heard a message through the media have reported use as compared to 40.0 percent and 34.2 percent of urban women, respectively. For those who reported easy access to a service outlet, 23.4 percent are users in rural areas and 36.4 percent in urban areas. This reflects a shortfall of the programme particularly in rural areas where use is quite limited among women even with knowledge of a service outlet and exposure to media messages. It may also be interesting to note that of women with difficult or no access to a service outlet, nearly 27 percent have reported use in urban areas as compared to only 4.8 percent in rural areas. Similarly, about 28 percent of urban women with no exposure to media message have reported use as compared to only 6.0 percent of rural women in the same category.

In order to examine the net effect of selected predictor variables on contraceptive use, the logistic regression results are presented in Table 3 for the total sample. Tables 4 and 5 show the results for urban and rural areas, respectively, to determine if the effects of the explanatory variables are different across the two settings. We considered a large number of socio-economic and demographic characteristics in addition to family planning service variables in the multivariate analysis of the factors affecting contraceptive use. After using various combinations of the selected variables in the regressions, we selected three basic models to show the effects of the theorised variables on contraceptive use. Model 1 presents the control variables, with living sons and living daughters replacing living children in order to compare their respective coefficients for evidence of son preference. Model 2 includes the theoretical variables: husband-wife communication, religious attitudes, and female autonomy. Model 3 adds to this the family planning programme indices to determine their effect on use after controlling for all other variables. No interactions between the covariates in the selected models were found to be significant.

Glancing at the results for the total sample in Table 3, we find that an exposure to urban living makes a significant difference in increasing use among couples as the log- 
Table 2

Percentages Using Contraceptives among Selected Sub-groups of Currently Married Non-pregnant Women Aged 15-49 Years: 1990-91.

\begin{tabular}{|c|c|c|c|c|c|c|}
\hline \multirow[b]{2}{*}{ Variables } & \multicolumn{2}{|c|}{ Total } & \multicolumn{2}{|c|}{ Urban } & \multicolumn{2}{|c|}{ Rural } \\
\hline & $\%$ using & $(\mathrm{N})$ & \% using & $(\mathrm{N})$ & $\%$ using & $(\mathrm{N})$ \\
\hline All Women & 14.4 & (5232) & 30.4 & (1628) & 7.1 & $(3604)$ \\
\hline \multicolumn{7}{|l|}{ Women's Age } \\
\hline $15-24$ & 6.8 & (1119) & 17.2 & (291) & 3.2 & $(827)$ \\
\hline $25-34$ & 13.9 & (2101) & 29.2 & (672) & 6.7 & (1429) \\
\hline $35+$ & 19.1 & (2012) & 37.5 & (665) & 10.0 & (1347) \\
\hline \multicolumn{7}{|l|}{ Living Children } \\
\hline Less than 4 & 8.4 & (2706) & 21.0 & (795) & 3.2 & (1911) \\
\hline 4 or more & 20.7 & (2526) & 39.4 & (833) & 11.6 & (1693) \\
\hline \multicolumn{7}{|l|}{ Wife's Education } \\
\hline None & 9.5 & (4108) & 22.0 & (881) & 6.1 & (3226) \\
\hline $\begin{array}{l}\text { Primary \& } \\
\text { Middle }\end{array}$ & 25.6 & (719) & 35.4 & (390) & 14.1 & $(330)$ \\
\hline Secondary + & 43.6 & (405) & 45.9 & (357) & 26.1 & (48) \\
\hline \multicolumn{7}{|c|}{ Husband's Education } \\
\hline None & 8.5 & (2503) & 21.8 & (464) & 5.5 & (2039) \\
\hline $\begin{array}{l}\text { Primary \& } \\
\text { Middle }\end{array}$ & 14.0 & (1497) & 26.6 & (447) & 8.6 & (1050) \\
\hline Secondary + & 26.8 & (1231) & 38.4 & (717) & 10.6 & (515) \\
\hline \multicolumn{7}{|l|}{ Region of Residence } \\
\hline Punjab & 15.6 & (3128) & 32.8 & (907) & 8.6 & (2221) \\
\hline Sindh & 15.3 & (1211) & 29.0 & (578) & 2.7 & (633) \\
\hline NWFP & 10.5 & (699) & 25.1 & (110) & 7.8 & (589) \\
\hline Balochistan & 2.6 & (193) & 8.4 & (32) & 1.4 & (160) \\
\hline \multicolumn{7}{|l|}{ Female Autonomy } \\
\hline Can’t go alone & 9.6 & (3892) & 24.0 & (937) & 5.0 & (2954) \\
\hline $\begin{array}{l}\text { Could go to } \\
\text { hospital alone }\end{array}$ & 28.3 & $(1340)$ & 39.2 & (691) & 16.8 & (649) \\
\hline \multicolumn{7}{|l|}{ Husband-wife } \\
\hline \multicolumn{7}{|l|}{ Communication } \\
\hline None & 6.4 & (4286) & 16.1 & $(1120)$ & 3.0 & (3166) \\
\hline Some & 50.6 & $(945)$ & 62.0 & $(508)$ & 37.3 & (437) \\
\hline \multicolumn{7}{|l|}{$\begin{array}{l}\text { Knowledge of } \\
\text { Service Outlet }\end{array}$} \\
\hline No & 1.5 & (2755) & 4.3 & $(435)$ & 1.0 & $(2320)$ \\
\hline Yes & 28.7 & (2476) & 40.0 & (1193) & 18.2 & (1284) \\
\hline \multicolumn{7}{|l|}{ Exposure to Media } \\
\hline No & 11.2 & (4104) & 27.9 & (978) & 6.0 & (3126) \\
\hline Yes & 25.8 & (1127) & 34.2 & (650) & 14.4 & $(477)$ \\
\hline \multicolumn{7}{|c|}{ Access to Service Outlet } \\
\hline Difficult/Other & 10.2 & (4166) & 26.8 & (1017) & 4.8 & (3149) \\
\hline Easy & 30.8 & (1066) & 36.4 & $(611)$ & 23.4 & (455) \\
\hline Yes & & & & & & \\
\hline
\end{tabular}

Source: Pakistan Demographic and Health Survey, 1990-91. 
Table 3

Logistic Regression Coefficients of the Effect of Selected

Predictor Variables on the Use of Contraceptives

(Currently Married, Non-pregnant Fecund Women Aged 15-49 Years)

\begin{tabular}{|c|c|c|c|}
\hline & Total Sam & & (Weighted) \\
\hline Predictor Variables & Model 1 & Model 2 & Model 3 \\
\hline Constant & $-6.81(.85)^{* * *}$ & $-3.76(.94)^{* * *}$ & $-4.84(.98)^{* * *}$ \\
\hline Women's Age & $.18(.05)^{* * *}$ & $.11(.06)^{*}$ & $.08(.06)$ \\
\hline Age Squared & $-.01(.00)^{* * *}$ & $-.00(.00)^{*}$ & $-.00(.00)$ \\
\hline \multicolumn{4}{|l|}{ Residence } \\
\hline \multicolumn{4}{|l|}{ Rural $^{\mathrm{a}}$} \\
\hline Always Urban & $1.39(.11)^{* * *}$ & $1.01(.13)^{* * *}$ & $.70(.13)^{* * *}$ \\
\hline Rural-Urban Migrants & $1.16(.13)^{* * *}$ & $.86(.18)^{* * *}$ & $.68(.15)^{* * *}$ \\
\hline \multicolumn{4}{|l|}{ Wife's Education } \\
\hline \multicolumn{4}{|l|}{ None $^{\mathrm{a}}$} \\
\hline Primary \& Middle & $.81(.12)^{* * *}$ & $.59(.13)^{* * *}$ & $.45(.14)^{* * *}$ \\
\hline Secondary \& Higher & $1.31(.15)^{* * *}$ & $.90(.17)^{* * *}$ & $.77(.18)^{* * *}$ \\
\hline \multicolumn{4}{|l|}{ Husband's Education } \\
\hline \multicolumn{4}{|l|}{ None $^{\mathrm{a}}$} \\
\hline Primary \& Middle & $.32(.11)^{* *}$ & $.21(.13)^{*}$ & $.12(.13)$ \\
\hline Secondary \& Higher & $.46(.13)^{* * *}$ & $.29(.14)^{* *}$ & $.17(.14)$ \\
\hline Living Sons & $.31(.03)^{* * *}$ & $.29(.03)^{* * *}$ & $.27(.03)^{* * *}$ \\
\hline Living Daughters & $.26(.03)^{* * *}$ & $.26(.04)^{* * *}$ & $.26(.04)^{* * *}$ \\
\hline \multicolumn{4}{|l|}{ Region of Residence } \\
\hline \multicolumn{4}{|l|}{ Punjab $^{\mathrm{a}}$} \\
\hline Sindh & $-.43(.11)^{* * *}$ & $-.22(.12)^{*}$ & $-.21(.13)$ \\
\hline NWFP & $-.06(.14)$ & $.05(.16)$ & $-.01(.17)$ \\
\hline Balochistan & $-1.55(.47)^{* * *}$ & $-.84(.49)^{*}$ & $-.76(.52)$ \\
\hline \multicolumn{4}{|l|}{ Husband-wife Communication } \\
\hline \multicolumn{4}{|l|}{ Some ${ }^{\mathrm{a}}$} \\
\hline None & & $-1.89(.10)^{* * *}$ & $-1.73(.10)^{* * *}$ \\
\hline \multicolumn{4}{|l|}{ Female Autonomy } \\
\hline \multicolumn{4}{|l|}{ Accompanied $^{\mathrm{a}}$} \\
\hline Could go to Hospital alone & & $.45(.10)^{* * *}$ & $.35(.11)^{* * *}$ \\
\hline \multicolumn{4}{|l|}{ Religious Beliefs $^{\mathrm{b}}$} \\
\hline Family Size, up to God & & $-1.22(.12)^{* * *}$ & $-1.05(.12)^{* * *}$ \\
\hline \multicolumn{4}{|l|}{ Family Planning Programme } \\
\hline \multicolumn{4}{|l|}{ Variables $^{\mathrm{b}}$} \\
\hline Knows Source of Service & & & $2.29(.18)^{* * *}$ \\
\hline Has Access to Service Outlet & & & $.27(.11)^{* *}$ \\
\hline Heard Media Message of FP & & & $.05(.11)$ \\
\hline -2 Log Likelihood & 3413.4 & 2704.2 & 2465.4 \\
\hline Model Chi Square (df) & 894.8(13) & 1604.1(16) & 1842.9(19) \\
\hline Goodness of Fit & 4829.2 & 4923.3 & 5938.9 \\
\hline Use Correctly Predicted & $86.0 \%$ & $89.0 \%$ & $90.0 \%$ \\
\hline Total $(\mathrm{N})$ & $(5232)$ & $(5232)$ & $(5232)$ \\
\hline
\end{tabular}

Source: Pakistan Demographic and Health Survey, 1990-91.

*Significant at .09 level; **at 0.5 level; *** at .001 level.

Figures in parenthesis are standard errors.

${ }^{a}$ Reference category.

${ }^{\mathrm{b}}$ The dummies created for these variables are defined in Table 1 and described in the text (pp. 8-10). 
Table 4

Logistic Regression Coefficients of the Effect of Selected

Predictor Variables on the Use of Contraceptives

(Currently Married, Non-pregnant Fecund Women Aged 15-49 Years)

Urban Areas

\begin{tabular}{|c|c|c|c|}
\hline Predictor Variables & Model 1 & Model 2 & Model 3 \\
\hline Constant & $-4.73(1.11)^{* * *}$ & $-1.62(1.25)$ & $-2.59(1.31)^{* *}$ \\
\hline Women's Age & $.13(.07)^{* *}$ & $.03(.08)$ & $-.01(.08)$ \\
\hline Age Squared & $-.01(.00)^{* *}$ & $-.00(.00)$ & $.00(.00)$ \\
\hline \multicolumn{4}{|l|}{ Wife's Education } \\
\hline \multicolumn{4}{|l|}{ None $^{\mathrm{a}}$} \\
\hline Primary & $.79(.15)^{* * *}$ & $.65(.17)^{* * *}$ & $.56(.17)^{* * *}$ \\
\hline Secondary & $1.29(.17)^{* * *}$ & $.96(.19)^{* * *}$ & $.81(.19)^{* * *}$ \\
\hline \multicolumn{4}{|l|}{ Husband's Education } \\
\hline \multicolumn{4}{|l|}{ None $^{\mathrm{a}}$} \\
\hline Primary & $.09(.16)$ & $-.02(.18)$ & $.06(.20)$ \\
\hline Secondary & $.40(.16)^{* *}$ & $.22(.18)$ & $.27(.19)$ \\
\hline Living Sons & $.31(.04)^{* * *}$ & $.32(.05)^{* * *}$ & $.30(.05)^{* * *}$ \\
\hline Living Daughters & $.23(.04)^{* * *}$ & $.25(.05)^{* * *}$ & $.26(.05)^{* * *}$ \\
\hline \multicolumn{4}{|l|}{ Region of Residence } \\
\hline \multicolumn{4}{|l|}{ Punjab ${ }^{\mathrm{a}}$} \\
\hline Sindh & $-.14(.13)$ & $-.04(.15)$ & $-.01(.15)$ \\
\hline NWFP & $-.15(.24)$ & $.07(.28)$ & $.11(.29)$ \\
\hline Balochistan & $-1.36(.66)^{* *}$ & $-.87(.71)$ & $-.79(.73)$ \\
\hline \multicolumn{4}{|l|}{ Husband-wife Communication } \\
\hline \multicolumn{4}{|l|}{ Some $\mathrm{a}^{\mathrm{a}}$} \\
\hline None & & $-1.63(.13)^{* * *}$ & $-1.56(.14)^{* * *}$ \\
\hline \multicolumn{4}{|l|}{ Female Autonomy } \\
\hline \multicolumn{4}{|l|}{ Accompanied $^{\mathrm{a}}$} \\
\hline Could go to Hospital alone & & $.31(.13)^{* *}$ & $.28(.13)^{* *}$ \\
\hline \multicolumn{4}{|l|}{ Religious Beliefs $^{\mathrm{b}}$} \\
\hline Family Size, up to God & & $-1.18(.16)^{* * *}$ & $-1.13(.16)^{* * *}$ \\
\hline \multicolumn{4}{|l|}{ Family Planning Programme } \\
\hline \multicolumn{4}{|l|}{ Variables $^{\mathrm{b}}$} \\
\hline Knows Source of Service & & & $2.23(.26)^{* * *}$ \\
\hline Easy Access to Service Outlet & & & $.64(.14)^{* * *}$ \\
\hline Heard Media Message of FP & & & $-.04(.14)$ \\
\hline -2 Log Likelihood & 1774.5 & 1461.8 & 1359.7 \\
\hline Model Chi Square (df) & $226.2(11)$ & $538.8(14)$ & $640.9(17)$ \\
\hline Goodness of Fit & 1584.1 & 1548.1 & 1579.8 \\
\hline Use Correctly Predicted & $71.4 \%$ & $78.5 \%$ & $81.0 \%$ \\
\hline Total $(\mathrm{N})$ & (1628) & (1628) & (1628) \\
\hline
\end{tabular}

Source: Pakistan Demographic and Health Survey, 1990-91.

*Significant at .09 level; **at 0.5 level; *** at .001 level.

Figures in parenthesis are standard errors.

${ }^{\text {a}}$ Reference category.

${ }^{\mathrm{b}}$ The dummies created for these variables are defined in Table 1 and described in the text (pp. 8-10). 
Table 5

Logistic Regression Coefficients of the Effect of Selected Predictor Variables on the Use of Contraceptives

(Currently Married, Non-pregnant Fecund Women Aged 15-49 Years)

Rural Areas

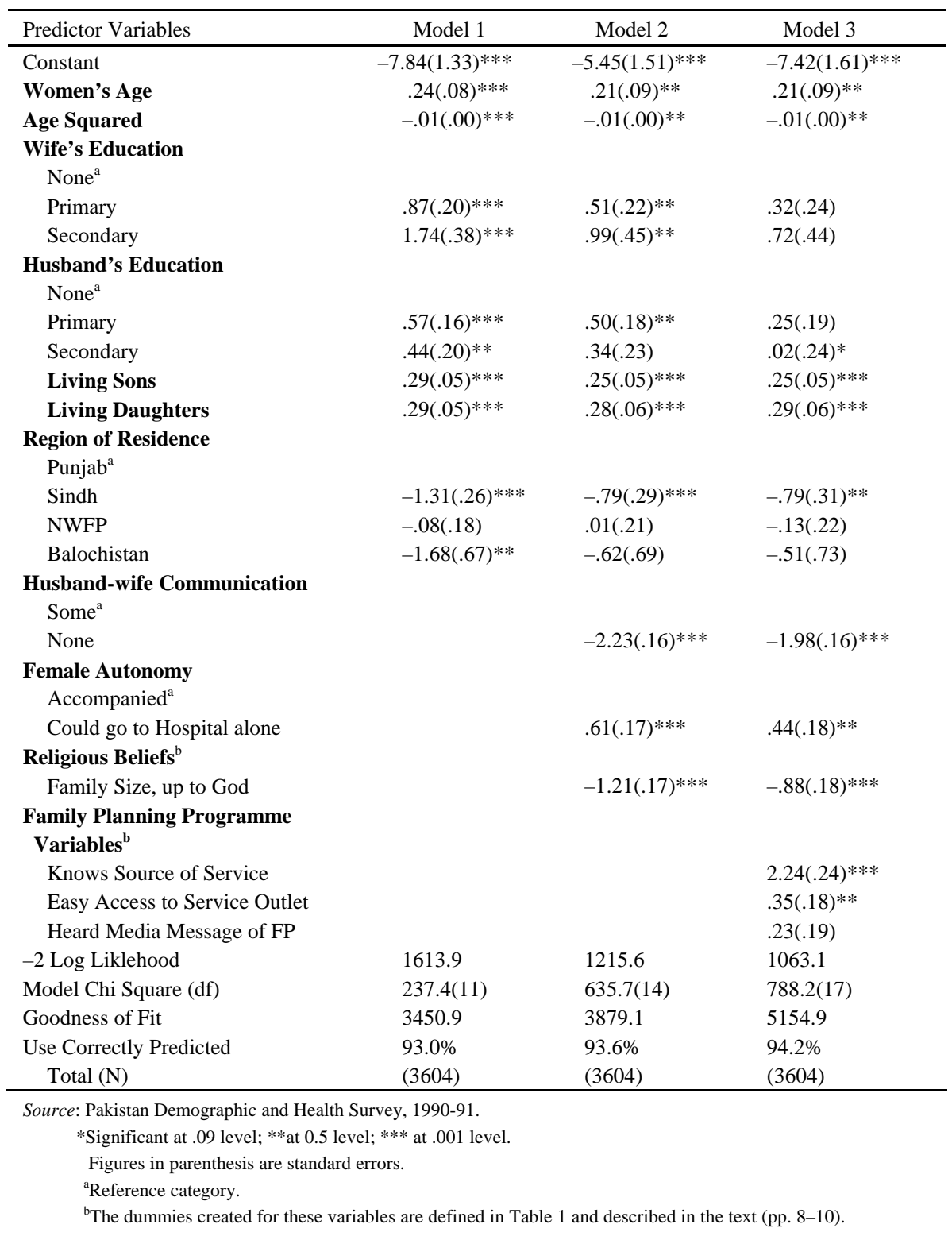


odds of using contraception increase by 1.39 for lifetime urban resident women and by 1.16 for rural to urban migrants as compared to rural residents. With the addition of the theoretical variables in Models 2 and 3, the coefficients of urban residence, whether lifetime or from rural to an urban area, are substantially reduced, but remain significant in predicting contraceptive use behaviour.

As expected, the log-odds of using contraceptives are much higher for educated women than those with no education across all models, although the explanatory power of wife's primary and secondary education considerably reduces in Models 2 and 3 when family planning variables are taken into account. Husbands' education does not appear to be an important factor in promoting contraceptive use. In fact, the pattern we observe is that education of husband's remains significant in Models 1 and 2, until family planning variables are entered in Model 3, making the husband's education effect disappear.

A non-linear relationship between women's age and contraceptive use is attained across all models. Although woman's rise in age appears to increase the likelihood of use, the difference becomes insignificant after controlling for all other variables in Model 3.

The effects of husband-wife communication, female autonomy, and religion are highly significant and in the expected direction. In Model 3, where all predictor variables are included, the net effect of the two programme variables, knowledge of source and easy access to service outlet, is highly significant, while that of having heard a media message is not important in predicting contraceptive use. The finding that knowledge of a source is the most significant predictor of use is not surprising given that the majority of women use modern methods which require having information about source of supply or services. Aside from knowledge of a source for family planning, communication between partners and religious beliefs have emerged as strong predictors of contraceptive use.

As for the regional variations in use, women in Sindh and Balochistan are clearly less likely to practise contraception when compared with those of the Punjab. However, after controlling for family planning variables, the differences between the provinces of residence become non-significant, implying that supply-related variables override the significance of variation between provinces.

Overall, the statistics of these results in Model 3 indicate 90 percent of use correctly predicted, with a substantial increase in the goodness of fit of the model.

The results of the urban analysis are presented in Table 4. On the whole, the covariates used in the models behave in almost the same way as observed for the total sample. The number of living sons as well as daughters is a highly significant predictor of contraceptive use and is virtually unaffected by the addition of other theoretical variables. However, the strength of the coefficient is relatively higher for living sons than for the daughters, as was hypothesised. This implies that having a certain number 
of sons increases the likelihood of use more among urban women when compared with living daughters. Women's age is not significant in explaining the variation in use for urban women.

As for women's education, the log-odds of using contraceptives increase by .79 for women with primary and middle education and by 1.29 for secondary and higher education when compared with the 'no education' category (Model 1). However, the addition of theoretical variables lessens the strength of these coefficients. On the other hand, the predictive power of husband's education, even at the secondary level, is totally eliminated by the addition of theoretical and family planning programme variables in Models 2 and 3.

The results also make it evident that the log-odds of contraceptive use among urban women reduce significantly by lack of husband-wife communication and fatalistic beliefs. Female autonomy shows a significant positive effect on contraceptive use, but its predictive power is less strong as compared to the communication and religious beliefs variables. As for the region of residence, it appears that stronger effects of the theoretical variables on use account for the regional differences than the region per se.

In Table 5, some factors are seen to distinguish the rural sample from the two previous samples. For example, women's age has emerged as a significant factor of contraceptive use for rural women as the coefficient remains significant across all models. As for women's education, women secondary and above education is important in affecting use while primary education is not, after controlling for all types of variables in Model 3.

In case of regional variations, women in all three provinces are less likely to use contraceptives when compared with those in Punjab, but it is only the women in Sindh who show a significant difference in use after taking into account all predictor variables.

The coefficients for living sons and daughters are highly significant and nearly identical in size for rural women. Given the extremely low level of contraceptive use in the rural areas, the data are inconclusive as to whether son preference does not exist or is not as strong as in urban areas. It appears probable that most women will have given birth to enough sons to satisfy a minimally desired number of children, and it is mostly women of high parity who are more likely to use contraception.

Factors like husband-wife communication and religious beliefs, however, are as consistent and significant in reducing the likelihood of use among the rural as among the urban women. As for the family planning service variables, knowledge of service outlet and easy access to service have again emerged as significant factors in increasing the likelihood of use, while media message has not shown a significant effect. On the whole, the predictive value of the model in the rural sample is the strongest, nearly 94 percent, with a significant increase in the goodness of fit in the full equation model. 


\section{DISCUSSION AND CONCLUSIONS}

The results of our analysis make it evident that contraceptive use in Pakistan is influenced by a number of demographic and socio-cultural factors, and that supplyrelated indices of family planning programme are crucial in increasing the likelihood of contraception. We may also infer from our analysis that increase in the level of women's education and hence more economic opportunities and autonomy for women, as well as increased level of husband-wife communication about family planning, can be conducive to the promotion of contraceptive use among couples.

What does this suggest for Pakistan's family planning programme? Given the importance of education for girls and its direct and indirect effects on contraceptive use behaviour, it must be acknowledged that neither public nor private sector family planning programmes have the authority or the resources to dramatically increase the educational level of women. The government must commit itself to universal education and the effort should continue at the policy level to make this a reality. It must, however, be borne in mind that, with the exception of adult literacy programmes, little benefit from improved educational opportunities, can be expected to accrue to young women who have already reached reproductive age. If the desirability to control fertility is to be legitimated among these women, they must be reached through such other means as strong supply services and educational campaigns for family planning.

In this context, while knowledge of family planning methods is quite widespread among women, the study reveals that knowledge of a source and easy access to a service outlet are strongly related to contraceptive use for both urban and rural women, reinforcing the fact that the availability of and access to services are critical factors for raising the level of contraceptive use. However, it appears that the programme has not reached a large proportion of couples and has failed to motivate those who have been reached. As Table 1 shows that while 47.3 percent of women reported knowledge of a family planning source, only 20 percent had easy access to a service outlet and 21.6 percent had heard a family planning message through the media. A good service delivery system is particularly lacking in the rural areas where the majority of the population lives. The estimate shows that 73 percent of the respondents who knew of a source did not have easy access to it. In the most densely populated region, the Punjab, clients must walk 9 kilometers, on average, to reach a service facility [Rukanuddin and Hardee-Cleaveland (1992)].

This evidence strongly suggests that an optimal use of family planning resources should focus on providing accessible and high quality services and on reaching couples through motivational campaigns. While it is true that interpersonal and communitybased communication approaches have not been widely tested in the field of family planning in Pakistan, small-scale studies [e.g., Kamal and Fowler (1991); Vernon et al. (1991)] have shown the potential for success and invite further exploration. The 
conclusion of the Turkish research, previously cited [Olson (1976)], was that modifying the "opportunity structure" of family planning programmes, by increasing their availability in rural areas, would be more successful than attempting to modify attitudes or beliefs. The present analysis supports the view that changing the attitudes/values and strengthening the programme are both important, and that the latter must be used to change the former.

Our finding that husband-wife communication on family planning matters is highly significant in explaining higher use of contraceptives is in agreement with the results of other studies [Shah (1974); Raju (1987); Oh (1988); Oheneba Sakji (1992)] and has ramifications for Pakistan's population programme. Couples who have never discussed family size preference, desire for additional children, or family planning, have never had an opportunity to learn from and influence each other's views. Dialogue between spouses may lead to a greater awareness, on the part of the husband, of the physical and other demands of excessive child-bearing, which can be influential in motivating couples to adopt contraception.

Our results also show that religious beliefs are important in lowering the likelihood of contraceptive use both among urban and rural women. This suggests that the programme should strive to clarify the misperceptions about family planning in the religion through enhancing motivational campaigns as well as seeking the cooperation and support of religious and community leaders, as this has been done successfully in other Muslim countries [Kamal and Fowler (1991); Sathar (1989)].

Overall, our analysis indicates that lack of spousal communication, less female autonomy, religious beliefs, and a preference for sons all contribute to a low level of contraceptive use, but it can be counteracted by a strong and better focused programme effort. As husbands play a decisive role in their wives' reproductive choices and behaviour in the Pakistani social setting, greater efforts are needed to influence the husbands' awareness of and attitude towards family planning. Direct appeals to men, targeting their economic interests and responsibilities, have shown success in increasing contraceptive use in some countries [Ringheim (1993)].

In sum, we say that while education for girls and women has to be expanded and strengthened, a more immediate benefit and return to the programme could be achieved by improving the supply and service strategies, particularly in rural areas, as well as by seeking the support of men and community leaders in accepting the adoption of family planning in Pakistan. 
Appendix

\begin{tabular}{|c|c|c|c|c|}
\hline \multicolumn{5}{|c|}{$\begin{array}{l}\text { Various Indicators of Fertility and Contraceptive Use among } \\
\text { Married Women of Reproductive Years: Pakistan 1975-1995 }\end{array}$} \\
\hline Indicators & $\begin{array}{c}1974-75 \\
\text { PFS } \\
\mathrm{N}=4949\end{array}$ & $\begin{array}{c}1984-85 \\
\text { PCPS } \\
\mathrm{N}=7,405\end{array}$ & $\begin{array}{c}1990-91 \\
\text { PDHS } \\
\mathrm{N}=6364\end{array}$ & $\begin{array}{c}1994-95 \\
\text { PCPS } \\
\mathrm{N}=7,922\end{array}$ \\
\hline Ever Used Contraceptives & 10.5 & 11.8 & 20.7 & 28.0 \\
\hline Currently Using Contraceptives & 5.2 & 9.1 & 14.0 & 17.8 \\
\hline Knowledge of any Method & 75.6 & 61.5 & 77.9 & 90.7 \\
\hline Want no more Children & 49.4 & 43.4 & 36.4 & 52.0 \\
\hline Children ever Born & 4.3 & 4.3 & 4.1 & $3.9 *$ \\
\hline Total Fertility Rate & 6.3 & 6.0 & 5.4 & $5.4^{*}$ \\
\hline
\end{tabular}

Source: Various Demographic Surveys.

PFS = Pakistan Fertility Survey, 1974-75.

PCPS= Pakistan Contraceptive Prevalence Survey, 1984-85.

PDHS $=$ Pakistan Demographic and Health Survey, 1990-91.

PCPS = Pakistan Contraceptive Prevalence Survey, 1994-95.

*: The number pertains to 1993 contraceptive prevalence survey.

\section{REFERENCES}

Afzal, Mohammad, F. M. K. Kiani, and Ali Mohammad (1993) An Indirect View of Fertility Changes in Pakistan. The Pakistan Development Review 32:4 Part II 1081-1096.

Ali, Syed Mubashir, and Abdul Razzaque Rukanuddin (1992) Family Size Preferences. Chapter in Pakistan Demographic and Health Surveys, 1990-91. Islamabad: National Institute of Population Studies/IRD/Macro International, Inc.

Arnold, Fred (1992) Sex Preference and Its Demographic and Health Implications. International Family Planning Perspectives 18:3 93-101.

Bertrand, J., J. Araya-Zelaya, R. Cisneros, and L. Morris (1982) Evaluation of Family Planning Communications in El Salvador. International Journal of Health Education 24:3 183-94.

Bulatao, R. (1993) Effective Family Planning Programmes. Washington, D. C.: The World Bank. 
Coale, Ansley J., and Susan Watkins (1986) The Decline of Fertility in Europe. Princeton: Princeton University Press.

Johnson, Nan E., and A. J. M. Sufian (1992) Effect of Son Mortality on Contraceptive Practice in Bangladesh. Journal of Biosocial Science 24: 9-16.

Kamal, I., and C. Fowler (1991) Community Organisation Implements Successful Male Involvement Project in Northwest Frontier Province, Pakistan. Unpublished paper. Pathfinder Fund.

Kane, M. M., and A. Larson (1982) Family Size Preferences: Evidence from the World Fertility Surveys. Reports on the World Fertility Survey 4. Washington, D. C.: Population Reference Bureau. 44 pp.

Khan, M. A., and I. Sirageldin (1977) Son Preference and Demand for Additional Children. Demography 14: 481-495

Mahmood, Naushin (1992) Motivation and Fertility Control Behaviour in Pakistan. The Pakistan Development Review 31:2 119-144.

Mahmood, Naushin (1992a) The Desire for Additional Children among Pakistani Women: The Determinants. The Pakistan Development Review 31:1 1-30.

Mahmood, Naushin, and Karin Ringheim (1993) Desired Fertility in Pakistan: What Is the Influence of Husbands? Paper presented at the Annual Meeting of the Population Association of America, Cincinnati, Ohio.

Ministry of Population Welfare/Population Council (1995) Pakistan Contraceptive Prevalence Survey, 1994-95. Basic Findings.

Mitchell, R. (1972) Husband-wife Relations and Family Planning Practices in Urban Hong Kong. Journal of Marriage and the Family 34:1 139-45.

Mukherjee, B. N. (1975) The Role of Husband-wife Communication in Family Planning. Journal of Marriage and the Family 37:3 655-67.

Nag, Moni (1991) Sex Preference in Bangladesh, India, and Pakistan and Effects on Fertility. New York: The Population Council. Population Council Research Division Working Paper No. 27.

National Institute of Population Studies (1992) Summary of Findings. Pakistan Demographic and Health Survey, 1990/1991. Islamabad: National Institute of Population Studies/IRD/Macro International, Inc.

Niruala, B. B., and S. P. Morgan (1994) Preference for Sons and Daughters in Benighat, Nepal: Implications for Fertility Transition. Paper presented at the 1994 Annual Meeting of Population Association of America. Miami, Florida.

Oh, H. Y. (1988) Impact Analysis of Husband-wife Conversation about the Number of Children. Journal of Population and Health Studies 8:1 58-72.

Oheneba, Sakyi, Yan (1992) Determinants of Current Contraceptive Use among Ghanaian Women at the Highest Risk of Pregnancy. Journal of Biosocial Science 24: 463-475. 
Olson-Prather, E. (1976) Family Planning and Husband-wife Relationships in Turkey. Journal of Marriage and the Family 38:2 379-385.

Pakistan Population Planning Council (1976) Pakistan Fertility Survey (First Report). Islamabad: Pakistan Population Planning Council.

Pineda, M. A., J. T. Bertrand, R. Santiso, and L. Morris (1981) Family Planning Communications in Guatemala: A Nation-wide Survey. (Unpublished.)

Rahman, Mizanur, and Julie DaVanzo (1993) Gender Preferences and Birth-spacing in Matlab, Bangladesh. Demography 30: 315-332.

Raju, S. (1987) Husband-wife Communication and Contraceptive Behaviour. Journal of Family Welfare 33:4 44-48.

Ringheim, Karin (1993) Factors that Determine Prevalence of Use of Contraceptive Methods for Men. Studies in Family Planning 24:2 73-79.

Robinson, Warren, M. A. Shah, and N. M. Shah (1981) The Family Planning Programme in Pakistan: What Went Wrong? International Family Planning Perspectives 7:3 85-92.

Rukanuddin, A. R., and Karen Hardee-Cleaveland (1992) Can Family Planning Succeed in Pakistan? International Family Planning Perspectives 18:3:109-121.

Sathar, Zeba (1989) Demand for Children and Family Planning. South Asia Study of Population Policy and Programmes: Pakistan. Islamabad: United Nations Population Fund.

Shah, N. M. (1974) The Role of Interspousal Communication in Adoption of Family Planning Methods: A Couple Approach. The Pakistan Development Review 13:4 452-469.

Shreeniwas, Sudha, and Naushin Mahmood (1995) Is There an Impact of Son Mortality on Contraceptive Use Patterns in Pakistan? Paper presented at the Annual Meeting of the Population Association of America. San Francisco.

Thapa, S., P. Lampe, and A. Abeykoon (1992) Assessing Potential Demand for Norplant Implants in Sri Lanka. Advances in Contraception 8:2 115-128.

Thomson, E. (1986) Marital Agreement in Fertility Goals. Centre for Demography and Ecology Working Paper 86-34, 9 pp. Madison, Wisconsin, University of Wisconsin.

Thomson, E., E. McDonald, and L. Bumpass, (1988) Couple Disagreement and Baby Boom Fertility. Center for Demography and Ecology Working Paper 88-28. October. Madison, Wisconsin: University of Wisconsin.

Vernon, R., Ojeda, G., and A. Vega (1991) Making Vasectomy Services More Acceptable to Men. International Family Planning Perspectives 17:2 55-60. 